\title{
IMPORTANCE OF SOFT SKILLS TRAINING AMONG COLLEGE STUDENTS: A META- ANALYSIS
}

\author{
Mridula N Murthy \\ M. S Ramaiah University of Applied Sciences, Bangalore, Karnataka, India
}

\begin{abstract}
The current analysis is a Qualitative Analysis of 17 previously studied researches on the importance of soft skills among college students focusing on engineering students. The review of literature supports that students at an undergraduate/ post graduate level require training in soft skills and leadership development. The researcher discusses the implementation of soft skills training among college students taking support of the literature review and her experience in the field. The discussion helps to understand the importance of nurturing students' talent right from college days, which is seen as a significant contributor to their soft skills. The results of this analysis reveal the significance of soft skills training and an application based academic environment in supporting the development of soft skills of college students.
\end{abstract}

Keywords: soft skills, leadership development, training, college students, qualitative analysis, metaanalysis

\section{INTRODUCTION}

'Employability' and 'Job Readiness' is one of the greatest aspects in every modern student's ambition. To get placed in one's dream job, one must possess both Academic and Soft Skill. Academics skills are the theoretical and technical knowledge. Transferring the theoretical knowledge into practical application is very crucial which can be acquired through enhancing Soft Skills.

Many academic institutions work towards bridging the gap between technical knowledge/skills and soft skills. Although not many institutions give prominence to these skills, there are some schools and colleges that have started giving importance to training their students in soft skills like communication and language skills, interpersonal and social skills, emotional intelligence, personal ethics, people management and leadership skills, time and stress management, negotiating and persuading skills, and many more.

'Soft Skills' refers to the skills which display maintaining healthy relationships with people around, or which portray how one manages the balance between work and life. Others words/phrases that can be used instead of Soft Skills are 'Transferable Skills' 'People Skills', 'Social Skills' and 'Interpersonal Skills'.

'Training' refers to the activities that are organized, which are aimed at exposing the recipients to an information and/or instruction to enhance their performance or to help them acquire the skills required to accomplish any challenges in both, their personal and professional lives.

\section{History and evolution of soft skills development}

About 900 years ago, unified religions offered the core source of interpersonal values and other soft skills (Alexis Kingsbury, 2015). People acquired how to conduct themselves in society, how to handle difficulty, and how to be prosperous, from their religious books and leaders. People didn't have many options on what they were preached, and were expected to follow. Adults were absorbing job skills though observing their master, often their parents.

In the next 800 years, private and public tutoring became available and more acceptable for children and adults to learn, resulting in greatly increased 
literacy. As non-religious institutions grew through the industrial and agricultural transformations, people's needs developed to more specific soft-skills direction (Alexis Kingsbury, 2015).

By 1950s, great business experts were educating people on how to better handle \& motivate employees. Organizations started developing training programs to help their employees to work better, identify and address concerns, and constantly improve (Alexis Kingsbury, 2015).

In the 1980s, videos on soft skills training became popular for catering for specific employee's needs such as customer orientation, effective communication and many more...

During the 1990s, the raise of internet meant that people access online training videos and research more easily, and be assisted with more specific information to cater to their training needs.

The early 2000s brought in innovation in multi-media training delivery, responsive and customized elearning and online evaluations (Alexis Kingsbury, 2015).

The mid - 2000s has brought soft skills training to the level of training college students at a young age.

\section{Soft skills training among college students}

The current analysis is a review of literature that aims to support that it is very essential for students to be trained in soft skills as much as they are in technical aspect of their education. The ultimate development of the students' learning lies in the way they handle people, conflicts and real life problems at work rather than how well they know their subject. The key way they can be innovative at work is when they are open to different ideas and views of others, be good listeners and communicators, confident, and possess healthy interpersonal and team skills.

Juanita Williams (1970) discussed the results obtained from a survey of college students where the students were asked to rank their subject training needs, and most participants answered technical writing as the second priority after management skills.

Albert P Rayan et al. (2008) observed that many students have speech anxiety when the course began. He suggested steps suggested by the students and taken by the trainers to help them come over their anxiety while speaking through which they can develop their communication skills.

C Scharff, et al (2009), addressed some of the difficulties faced in getting students to present a quality product at the end the semester which is a yearly project taken on alongside with the core curriculum. The author suggested including soft skills and presentations skill training as a compulsory part of the curriculum in the educational model.

Taking it a step forward, Latika Sahni (2011) described the relevance of Management Development Programs even for the students pursuing professional courses. The author described a design for suitable training program and explained several influencing factors of managerial skills on professionalism. She revealed significant impact of the training on certain skills observed in her study that were necessary for managerial skills.

Roxanne Hori (2012) shared an instance of talking with representatives from organizations and gathering their thoughts on the most important skills needed on the job which were soft skills such as communication, interpersonal skills etc. Based on the response from the representatives, the author discussed the necessity of soft skills as crucial criteria to search for a job.

Jane Freeman (2013) shared his thought that students largely desire training in two areas of oral communication: presentation skills and professional communication skills. The author described specific challenges to Non Fluent English Speaking students to having conversations, and suggested exercises that can help them to enhance their confidence and fluency in Communicative English.

Geana W Mitchell et al (2013) discussed the results of a survey on level of perceived importance of soft skills required for success and their influence on growth at the work place. The findings indicated that the participants (MBA students) perceived all the softer skills to be very important in the present workforce.

Sherry Robinson et al (2014) talked about how soft skills such as creativity, critical thinking, logical thinking, efficiently working in team are as important as technical and hard skills to be a successful entrepreneur. The author argued that it could be a challenge to teach and learn although it was suggested that students perform better when they are 
taught/ trained with softer skills and to take and manage risks rather than when they focus only on bookish knowledge.

J Parasuraman et al. (2015) focused on the most important to attain employability and job related skills. The author distinguished, implied and transformed some sets of skills to use the potential prospect available. The study concluded that practical knowledge execution and performance in campus projects help students in developing corporate skills.

The above studies stated the significance of training among college students. However, the current analysis gives importance to engineering students as the author trains the engineering students.

\section{Soft skills training among engineering students}

Engineering is a field of opportunities to professionals who are skilled and trained. However, the candidates pay least emphasis on the soft skills. The opportunity of soft skills goes beyond personality-driven traits and communication skills. These skills make an engineer smarter, stronger and prepare him/her for the unpredictable and changing circumstances he might have to endure.

Sanjeev Kumar et al (2007) shared his views on inculcating leadership in engineers and its association to their education, service-learning and problembased learning instructions as they relate to engineering education. The author also stated examples of executing these instructions in an engineering course.

Agatha Gimore (2008), talks about how colleges, prepare their student in the technical aspects of entrylevel for a job, but don't focus on other softer skills like professionalism and job readiness. She went a step forward and stated the need in IT companies where the employers look for candidates who display certain job related soft skills. It was stated that many employers were aware lot of candidates waiting to get a job but felt that most of them were not 'qualified' where they referred to qualified for job related soft skills.

John V. Farr et al. (2009) explored the transformation of engineering career in the competitive environment and addressed the importance of leadership in the progression of the career. The findings suggested ways to promote leadership qualities throughout an engineering career.
K.P.S.K. Ilavenil (2011) studied the deep links between the English language and engineering education in India. The study focused on the dominant employability practices. It also threw light on the emphasis given for communication skills in English. The study further explored and explained the ways in which the English can be included in engineering curriculum to expand the focus from employability to justifiable development and engineering principles and ethics.

M.S Rao (2014) shared in his paper about bridging the gap between the academic campus and industry, among the Engineering and Management students. It was found that an effective coordination is necessary among the faculty members, students, corporate and the Directors of Academic Institutions to enhance employability and soft skills among students. This study throws light on the role of Training and Placement Officer (TPO) in the academic institutions to enhance employability.

The above stated studies stated the implementation of soft skills training in the engineering curriculum so as to create job ready engineers.

\section{NEED FOR THE ANALYSIS}

In today's competitive world, to get hired in a reputed organisation, fresher need to have an overall combination of knowledge and skills. Unlike earlier, employers not only look at the qualification and scores of the candidates but also seek for the skills they possess. It is very important that students enter their career with softer relationship building and interpersonal skills that help them collaborate, communicate and negotiate well in an organisation.

These people skills are very critical for all the employees to face most of the job related challenges like communicating effectively, working in a team, building networks, acquiring leadership quality, voicing out opinions in a meeting, etc. Time management, stress management, conflict resolution, problem solving and effective and ethical decision making are the other most important aspects the youngsters require to build their name in their career. Training them in these skills, in the college level will not only help them in performing well in their assignments and projects in college but also prepares them to be job ready. 
Globalisation and working in culturally diverse teams are the greatest opportunities in today's corporate world. The employees are expected to understand the difference in cultures and accents and respect the diversities and also make themselves clear with effective communication.

The current analysis, attempts to understand and throw light on the prominence of introducing these soft/ people skills in students and let them out with flying colours not only with a degree/certificate that will get them a job but also the qualities that would make them assets for the team/ organisation they work for.

\section{DISCUSSION}

The current analysis throws light on how technical/ hard skills are necessary for students to start their career; it's the soft skills that enable them in winning over all the challenges in their job. The researcher focuses on engineering students as she is a Trainer (Handling the Engineering Students) in a well-known university in Bangalore, India which works towards producing job ready graduates.

The more one displays people skills, the more one has chances to grow in our careers. Colleges and Universities have to make attempt to bridge the gap between the academic campus and industry. One of the ways it can be done is by building an effective coordination between the faculty members, students, corporate and the Directors of academic institutions to understand what exactly the industries need other than hard core knowledge and work towards enhancing employability and soft skills among students. Academic institutions work towards enhancing employability of students although most of them start soft skills training during the time of the placements.

The researcher in her University makes an attempt to create an environment for the student to display the key soft skills from the first year of their courses. As a part of the University, the researcher believes education should train students not only in the lower levels of learning (Remembering and Understanding) but also in the higher order of learning (Evaluation and Creation). To reach the level of learning where the students need to create, they need to depict a lot of soft skills such as effective listening skills, team work, ready to risk and fail, effective communication skills (Reading Writing, Speaking and Listening), ethics, etc. These skills are necessary for anyone to be broad minded to step out of the box and innovate to contribute to the society. Colleges and Universities should train the students in these skills to generate higher level of thinkers and learners.

In the current scenario of many multinational companies coming up due to globalization, it is very likely that employees will have to interact and work with people from different countries and cultures. One of the ways to work well in a diverse, multicultural team is to understand diversities and respect the differences in the culture, accent, ideas and opinions. Open-mindedness (the ability to step out of one's own comfort zone) is one of the key soft skills required to survive in the global industries. The researcher in her university has observed a lot of cultural differences in the classes she handles and encourages the students to work together and overcome making fun and pulling down people from different cultures and their accents. Colleges can encourage healthy behavior among students by encouraging them to work on group projects where the teams are formed by the teachers rather than the students choosing with whom they want to work. This would make them ready to work with different teams in their jobs.

Good fluency and knowledge of English is another challenge in multi-national and multi-cultural industries. Colleges have to identify students who lack English fluency and basic skills and help them in develop confidence in speaking and expressing in the language. Many students get anxiety and hesitate taking in English. The researcher has come across students who come from different backgrounds who fear talking in English. These students are encouraged to talk in English and allowed to make mistakes and are corrected right then. A token of appreciation is given to them on improving which would increase their confidence and decrease the hesitation and anxiety towards the language. These students volunteer to improve their English skills as they know how important it is for them to achieve their bigger goals. Students should be made to realize the importance of fluency in English and also made to understand that mistakes are a part of learning and English like any other language can be learnt when one speaks and tries to understand with passion rather than with a force or fear. 
Perceived importance of soft skills among students is very important to train them and also make the training effective. The students should be introduced with live examples and cases to make them understand and/or change their perception on how important soft skills are for them. They should be made aware that " $85 \%$ of people get fired due to lack of soft skills whereas only $15 \%$ of them get fired because of their hard/ technical skills." Only when they perceive and feel that these skills are actually important and would help them in reaching where they want to be in their profession, they will be better recipients of the training given to them.

Another aspect that needs to be looked into while molding the students is Professionalism. The students need to possess a good conduct, behavior, formal communication and other team skills to display good evidence of professionalism is expected and will be appreciated in the industries. Colleges need to encourage and train students in professional/ formal communication (Oral/ Written). In the researcher's University, the students are trained and made aware about the different channels of professional/ Business Communication and how to choose the appropriate channel of communication based on situations. Colleges should bring in awareness of professional and business processes that generally happen in the work place through case studies, role plays and sharing of real life scenarios.

Emotional intelligence is another key soft skill that enables an individual to work in a team. One of the challenges that most freshers in the industry face is handling and reacting to constructive feedback. Students should be trained to respond (not react) to feedback in a productive way rather than taking it to heart and being upset. One of the main reasons why youngsters don't take feedback well is that they have been "drilled" to be perfect and make no mistakes. Making minor mistakes and getting a feedback makes them feel low and insulted displaying unhealthy and emotional intelligence. One way to help them overcome this perception is to allow and encourage them to take risks and make mistakes, give feedback and encourage them to learn from their mistakes.

Promoting of leadership and managerial qualities among college students in a very age is necessary as that is one of the most important qualities that employers seek in potential candidates. Soft skills also help in improved Productivity and efficiency in performance and make students job ready and employable by the time they pass out of college.

\section{SUMMARY}

The current analysis can be summarized as follows:

- Technical skills can get one a job but soft skills is the secret that can get one a promotion and grow in career.

- Colleges should include soft skills as a part of the curriculum during the course of the students' degree tenure bridging a gap between campus and industry.

- Students should be trained to understand and handle cultural and lingual diversities and also differences in ideas.

- Self-confidence can be one of the traits that would influence the level of soft skills in students.

- Students should be encouraged to talk in English fluently and without any hesitation and anxiety.

- Emotional Intelligence is a very important soft skill that should be imbibed in the students

- Teachers should encourage students to take risks and make mistakes which would help the students to handle failure and take constructive feedback which are a part of work life.

\section{CONCLUSION}

Just like how a tree is not stable without well developed roots, it is seen through the current analysis that soft and people skills are the roots that give rise to a strong and stable career tree in an individual's life. Based on the analysis, the following conclusions can be made for future applications:

- The analysis has suggested colleges as an important factor for providing a platform for the growth of soft skills. Hence, the analysis can help colleges to recognize key skills and nurture the same by interacting, spreading awareness and training the students. 
- To train teachers to imbibe soft skills in the curriculum itself, rather than looking at it from extra-curricular activities is one of the suggestive outcomes of the analysis.

- A module on Soft skills training among college students could be brought about by using the themes outlined in the current analysis. Setting an environment where the students can display key soft skills same could be the aim of such a module.

- The analysis also suggests the importance of role models in students. The importance of role models can be brought about in the training modules.

- Creating an environment which enables the development of soft skills, where the students is allowed to take risks, make mistakes and learn.

\section{LIMITATIONS}

The current analysis is a Meta-Analysis.

Future studies could include methodology like surveys and tests to assess student's level of displaying soft skills and design interventions and training modules to enhance the same.

\section{IMPLICATIONS}

The current analysis can lead to further research in understanding soft skills development as a continuous process. Research can be conducted in the following areas:

- A more detailed analysis can be conducted to see the development of soft skills in students and understand the different factors that influence the development and being job ready.

- The analysis reveals the importance of a training module which will help enhance and encourage soft skills development. Studies in future can focus on the influence of these modules on the employability of the students.
- College was also noted to be an important factor in enhancing soft skills. Although colleges have encouraged soft skill training, there needs to be more focus on importance of enhancing soft skills in students.

- A research model enhancing the skills in students, which throws light on the development of people skills can help understand the importance of these skills in the students being job ready and employable.

Thus, it can be summarised from the implications that the current analysis can help in creating employable, job ready freshers who would make not only their college but also their employers proud and be assets to their team.

As Nelson Mandela stated "Lead from the back - Let the others believe they are in front", the students have to be given the responsibility to learn and create new ideas and take the ownership to their own development through the training initiatives designed by their teachers/ colleges to make them confident.

\section{REFFERENCES}

Agatha Gimore, 'Educating to Ensure Soft Skills', Certificate Magazine (March 2008), pg. 10

Albert P'Rayan, Ramakrishna T. Shetty, 'Developing Engineering Students' Communication Skills by Reducing their Communication Apprehension' English for Specific Purposes World, 4 (20):7, 2008, pg. 1-24

Brazil, Donna M., John V. Farr, 'Leadership Skills Development for Engineers', Engineering Management Journal, 21:1, 2009 pg. 3-8

Freeman, Jane. 'The Science of Conversation: Training in Dialogue for NNS in Engineering', IEEE Transactions on Professional Communication. Sep2003, Vol. 46 Issue 3, pg. 157-67

Gotel, O. Kulkarni, V. Say, M. Scharff, C. Sunetnanta, T., 'A Global and Competition-Based Model for Fostering Technical and Soft Skills in Software Engineering Education', Software Engineering Education and Training, 2009. CSEET '09. 22nd Conference, 17-20 Feb 2009

Hori, Roxanne, 'Why Soft Skills Matters' Bloomberg.com. 12/6/2012, pg. $4-4$

J Parasuraman, N Hari Prasad, 'Employability is an option aptly focused through skill development', The IUP Journal of Soft Skills, 9:2, 2015 pg. 22-43

K.P.S.K. Ilavenil, 'English and Engineering Education: The Need to Move Beyond the Employability Discourse' MJAL1:5 September 2009, pg. 264-74 
Latika Sahni, 'The Impact of Soft Skill Training Induction Programme on New Enterants', BVIMR Management Egde, 4:2 (2011) pg. 40-7

Mitchell Geana, Pritchett, Christal C. Skinner, Leane B. 'The Importance of the Integration of Soft Skills into the Curriculum as Identified by MBA Students' Academy of Business Research Journal. 2013, Vol. 1, pg. 67-81.

Rao, M.S, 'Enhancing Employability in Engineering and Management Students through Soft Skills', Industrial \& Commercial Training. 2014, 46:1, pg. 42-8

Sanjeev Kumar, J. Kent Hsiao, 'Engineers Learn "Soft Skills the Hard Way": Planting a Seed of Leadership in Engineering Classes', Leadership and Management in Engineering, 2007, pg. 18-23
Sherry Robinson, Hans Anton Stubberud, 'Teaching Creativity, team work and other soft skills for entrepreneurship' Journal of Entrepreneurship Education, 17:2, 2014 pg. $186-97$

Williams, Juanita $\mathrm{H}$, 'Testing the Writing Skills of Engineering and Science Students' Journal of Business Communication. Fall 70, 8:1, pg. 25-36

Web references

Alexis Kingsbury, Soft-skills training attendance through history, http://www.makinggreatness.com/soft-skillstraining-attendance-through-history/, 2015 